\title{
Assessment of Antioxidant Reserves and Oxidative Stress in Cerebrospinal Fluid after Severe Traumatic Brain Injury in Infants and Children
}

\author{
HÜLYA BAYIR, VALERIAN E. KAGAN, YULIA Y. TYURINA, VLADIMIR TYURIN, \\ RANDALL A. RUPPEL, P. DAVID ADELSON, STEVEN H. GRAHAM, KERI JANESKO, \\ ROBERT S.B. CLARK, AND PATRICK M. KOCHANEK
}

\begin{abstract}
Department of Anesthesiology and Critical Care Medicine and Department of Pediatrics [H.B., R.A.R., R.S.B.C., P.M.K.], Department of Neurosurgery [P.D.A.], Department of Neurology [S.H.G.], Department of Environmental and Occupational Health and Pharmacology [V.E.K., Y.Y.T., V.T.], University of Pittsburgh School of Medicine, Pittsburgh, Pennsylvania, U.S.A.; Safar Center for Resuscitation Research, University of Pittsburgh Medical Center, Pittsburgh, Pennsylvania, U.S.A. [H.B., R.A.R., K.J., R.S.B.C., P.M.K.]; Children's Hospital of Pittsburgh, Pittsburgh, Pennsylvania, U.S.A. [H.B., R.A.R., P.D.A.,
\end{abstract} R.S.B.C., PM.K.]

\begin{abstract}
Studies in experimental traumatic brain injury (TBI) support a key role for oxidative stress. The degree of oxidative injury in clinical TBI, however, remains to be defined. We assessed antioxidant defenses and oxidative stress in pediatric TBI by applying a comprehensive battery of assays to cerebrospinal fluid samples. Using a protocol approved by our institutional review board, 87 cerebrospinal fluid samples from 11 infants and children with severe TBI (Glasgow Coma Scale score $\leq 8$ ) and 8 controls were studied. Cerebrospinal fluid was drained as standard care after TBI. CSF was assessed on d 1, 2, and 5-7 after ventricular drain placement. Biochemical markers of oxidative stress included $\mathrm{F}_{2}$-isoprostane and protein sulfhydryl (detected by ELISA and fluorescence assay, respectively). Antioxidant defenses were measured by determination of total antioxidant reserve (via chemiluminescence assay), and ascorbate (via HPLC) and glutathione (via fluorescence assay) concentrations. Free radical production (ascorbate radical) was assessed by electron paramagnetic resonance spectroscopy. $\mathrm{F}_{2}$-isoprostane was markedly increased versus control, maximal on d 1 (93.8 \pm $30.8 \mathrm{pg} / \mathrm{mL}$ versus $7.6 \pm 5.1 \mathrm{pg} / \mathrm{mL}, p<0.05)$. Total antioxidant reserve was reduced versus control. Reduction was maximal on
\end{abstract}

\section{ABSTRACT}

d 5-7 $(81.8 \pm 3.7 \mu \mathrm{M}$ versus $178.9 \pm 2.2 \mu \mathrm{M}, p<0.05)$. Ascorbate was remarkably reduced $(53.8 \pm 8 \mu \mathrm{M}$ versus 163.8 $\pm 21 \mu \mathrm{M}$ on $\mathrm{d} 1, p<0.05)$. Ascorbate depletion was likely associated with its free radical oxidation, as evidenced by electron paramagnetic resonance spectroscopy. Glutathione levels increased on $\mathrm{d} 1$, then decreased versus control $(0.19 \pm 0.05 \mu \mathrm{M}$ versus $1.2 \pm 0.16 \mu \mathrm{M}, p<0.05)$. This is the first comprehensive study of antioxidant reserve and oxidative injury in clinical TBI. Progressive compromise of antioxidant defenses and evidence of free radical-mediated lipid peroxidation are noted. These markers could be used to monitor antioxidant strategies in clinical trials. (Pediatr Res 51: 571-578, 2002)
TBI, traumatic brain injury
Abbreviations
CSF, cerebrospinal fluid
EPR, electron paramagnetic resonance spectroscopy
LMWA, low-molecular-weight antioxidants
SOD, superoxide dismutase
GSH, glutathione
GCS, Glasgow Coma Scale

AAPH, 2,2'-azobis(2-amidinopropane)dihydrochloride
Trauma is the leading cause of death in children. Severe TBI is an important contributor to this mortality and to associated

\footnotetext{
Received July 11, 2001; accepted December 7, 2001.

Correspondence: Patrick M. Kochanek, M.D., Safar Center for Resuscitation Research, 3434 Fifth Avenue, Pittsburgh, PA 15260, U.S.A; e-mail: kochanekpm@anes.upmc.edu Supported, in part, by the University of Pittsburgh Center for Injury Control and Research/Centers for Disease Control (P.M.K.), Grant NS30318 from the National Institutes of Health (P.M.K.), and the Department of Anesthesiology and Critical Care Medicine, University of Pittsburgh School of Medicine (H.B.).
}

morbidity. TBI triggers a pathway of neuronal death involving loss of cellular calcium homeostasis, tissue acidosis, and oxidative stress (1). Data from experimental TBI support an important role for oxidative injury in early neuronal and vascular damage after TBI (2-5), as well as in secondary delete-

Presented at the 30th International Society of Critical Care Medicine Symposium, San Francisco, CA, U.S.A., February 9-13, 2001; also presented, in part, at the annual meeting of the Pediatric Academic Societies, Baltimore, MD, U.S.A., April 28-May 1, 2001. 
rious processes associated with inflammatory mediators and neutrophil-, macrophage-, and parenchyma-mediated inflammation $(6-10)$. Although some clinical trials have targeted oxidative stress, to date, no studies including infants and children have addressed the source and nature of free radical intermediates and the endogenous defense mechanisms that protect against oxidative stress in clinical TBI.

Free radical production is common to a number of biochemical pathways that are activated in a variety of TBI models. These involve the eicosanoid cascade (via phospholipase $\mathrm{A}_{2}$ and cyclooxygenase-2), activation of $N$-methyl-D-aspartate, and other excitatory amino acid receptors with accumulation of intracellular calcium and release of cytokines (11). Because all of these pathways result in the production of free radicals, it is likely that free radicals play a central role in mediating secondary damage. The brain is particularly vulnerable to oxidative stress because of its high rate of oxidative metabolic activity, intense production of reactive oxygen metabolites (mandating a high antioxidant capacity) (12), nonreplicating nature of neurons, and high membrane-to-cytoplasm ratio (13). High levels of polyunsaturated fatty acids in the membrane lipids of the brain are a source for lipid peroxidation reactions (14). The brain also contains high levels of transition metals, such as iron, that are capable of catalyzing the production of reactive radicals (15). Free radicals have been shown to affect not only classical targets such as lipids and proteins, but also gene transcriptional processes associated with pathologic events. Activator protein- 1 and nuclear factor- $\kappa \mathrm{B}$, both transcriptional factors, are activated by free radicals $(16,17)$. In addition, several cell-regulatory mechanisms are known to be affected by oxidative stress (18). Dysregulation of both cellular homeostasis and intracellular transduction cascades because of the oxidative damage to calmodulin-regulated enzymes has been reported (19).

Antioxidants act in a concerted way in normal brain. Trauma not only eliminates regulation of antioxidant mechanisms but may also convert these mechanisms into pro-oxidant ones through its ability to disrupt fine compartmentalization. Brain tissue contains various types of antioxidants. The antioxidant system can be classified into two major groups: enzymes and LMWA. The enzymes include a limited number of proteins, SOD, catalase, and peroxidase, as well as some supporting enzymes. The levels of the enzymes vary in different brain regions and among various species (14). The protective role of endogenous antioxidant enzymes in ischemic brain injury was shown by Chan (20). Transgenic mice overexpressing copperzinc SOD and anti-apoptotic Bcl-2 were found to be protected in a model of brain ischemia/reperfusion injury, whereas knockouts, deficient in SOD, were more vulnerable to ischemic injury.

The LMWA in the brain include a concerted system of water- and lipid-soluble molecules like GSH, ascorbic acid, histidine-related compounds (carnosine, homocarnosine, and anserine), melatonin, uric acid, lipoic acid, and tocopherols (vitamin E) (14). These are extremely important in minimizing oxidative stress. However, the cell can synthesize only a limited number of these molecules (i.e. GSH, carnosine). The majority of LMWA are derived from dietary sources. Notably, the ascorbate concentration is unusually high in the brain (15).

A number of therapeutic approaches based on scavenging free radicals have been attempted in both experimental (21-24) and clinical (25) TBI. The efficacies of SOD and catalase are limited by their inability to cross the blood-brain barrier and penetrate cells $(21,26)$. Although tirilazad mesylate has been shown to be effective in experimental models of cerebral ischemia (27), subarachnoid hemorrhage (28), and hypovolemic shock (29), it showed largely negative results in the treatment of severe TBI in adult patients $(30,31)$.

Based on previous work done by our group showing significantly enhanced generation of lipid peroxidation products and consumption of antioxidants after experimental TBI in rats (9), we hypothesize that severe TBI in infants and children results in a reduction in total antioxidant reserve, ascorbate, and GSH concentration, whereas protein oxidation and levels of $\mathrm{F}_{2^{-}}$ isoprostane, a specific marker of lipid peroxidation, are increased in CSF versus control.

In the present study, we report marked and sustained decreases in total antioxidant reserve, ascorbate, and GSH concentration after TBI. Similarly, we provide evidence of free radical-mediated lipid peroxidation and protein oxidation in CSF after severe TBI in infants and children. To our knowledge, this is the first comprehensive study of total antioxidant reserve and markers of oxidative injury in either pediatric or adult TBI. Our findings suggest the need for additional investigations into the role of therapies targeting free radicalmediated damage in experimental and clinical TBI. Finally, the CSF markers used in this study could be used to assess the effect of therapies on oxidative stress after TBI in patients.

\section{METHODS}

Patient selection and data collection. This study was approved by the Institutional Review Board of the Children's Hospital of Pittsburgh, and informed consent was obtained from parents for sample collection. All patients with severe TBI (GCS score $\leq 8$ ) admitted to the Children's Hospital of Pittsburgh were treated with ventricular catheter insertion, and CSF was drained continuously. In accordance with our TBI treatment protocol, all patients were also intubated and mechanically ventilated to a partial pressure of $\mathrm{CO}_{2}$, arterial, of $30-35 \mathrm{~mm} \mathrm{Hg}$. They received sedation with narcotics (fentanyl or morphine sulfate) and pharmacological paralysis with vecuronium bromide to keep their intracranial pressure and cerebral perfusion pressure in the age-appropriate target range. Barbiturates were used as needed for refractory intracranial hypertension. One patient in the study was treated with therapeutic hypothermia $\left(32-33^{\circ} \mathrm{C}\right)$ as part of a randomized controlled trial. CSF samples $(n=87,0.5 \mathrm{~mL})$ from 11 infants and children with severe TBI, collected at the time of intraventricular catheter insertion and then daily until the time of catheter removal, were studied. Control CSF samples were obtained from eight age-matched controls who underwent lumbar puncture to rule out meningitis. None of these patients had evidence of meningitis (as determined by negative cultures and lack of pleocytosis), TBI, hypoxia-ischemia, or seizures. Samples 
were centrifuged for $10 \mathrm{~min}$ at $5000 \times g$ and immediately frozen at $-70^{\circ} \mathrm{C}$ until the time of analysis.

Demographic and clinical parameters [age, gender, mechanism of injury (accident versus abuse), admission GCS score, and outcome (survival versus death)] were recorded for each patient. Appropriate safeguards were in place for patient confidentiality, all samples were coded, and patients' names were maintained in a locked file.

Determination of $\boldsymbol{F}_{2}$-isoprostane. $\mathrm{CSF} \mathrm{F}_{2}$-isoprostane content was measured by a commercial enzyme immunoassay kit (Cayman Chemical, Ann Arbor, MI, U.S.A.) with a detection limit of $2 \mathrm{pg} / \mathrm{mL}$. To exclude interference of CSF with $\mathrm{F}_{2^{-}}$ isoprostane measurements, values were obtained in two series of determinations carried out in either standard buffer or in CSF samples spiked with known amounts of $\mathrm{F}_{2}$-isoprostane. No difference in results between these two approaches was found.

Fluorescence assay of protein sulfhydryls and GSH. The concentration of sulfhydryl groups (GSH plus protein sulfhydryl groups) in CSF samples was determined using ThioGlo-1 (Convalent Associates, Inc., Woburn, MA), a maleimide reagent that produces a highly fluorescent product upon its reaction with sulfhydryl groups (32). A standard curve was established by addition of GSH $(0.04-4 \mu \mathrm{M})$ to $50 \mathrm{mM}$ disodium phosphate buffer ( $\mathrm{pH}$ 7.4) containing $10 \mu \mathrm{M}$ ThioGlo-1. GSH content was estimated by an immediate fluorescence response observed upon addition of ThioGlo-1 to CSF. Levels of total protein sulfhydryls were determined as an additional fluorescence response after addition of $4 \mathrm{mM}$ SDS to the same sample. A Cytofluor 2350 fluorescence plate reader (Millipore Corporation, Marlborough, MA, U.S.A.) was used to detect fluorescence using excitation and emission wavelengths of $388 \mathrm{~nm}$ and $500 \mathrm{~nm}$, respectively. The data acquired were exported from the spectrophotometer using Cytofluor software.

Chemiluminescence measurements of total antioxidant reserve in CSF. Total antioxidant reserve in CSF was assayed by chemiluminescence produced in the presence of luminol and a source of peroxyl radicals, as described by Tyurina et al. (33). A water-soluble azo-initiator, AAPH, was used to produce peroxyl radicals at a constant rate. Oxidation of luminol (400 $\mu \mathrm{M})$ by AAPH-derived peroxyl radicals in $50 \mathrm{mM}$ disodium phosphate buffer $\left(\mathrm{pH} \mathrm{7.4)}\right.$ at $37^{\circ} \mathrm{C}$ was assayed by monitoring the chemiluminescence response. The reaction was initiated by addition of AAPH. A delay in the chemiluminescence response, which is caused by interaction of endogenous antioxidants with AAPH-derived peroxyl radicals, was observed upon addition of CSF. Based on the known rate of peroxyl radical generation by AAPH, the amount of peroxyl radicals scavenged by endogenous antioxidants was determined. A Microlite ML 1000 microtiter plate luminometer (Dynatech Labs, Chantilly, VA, U.S.A.) was used for these determinations.

HPLC assay of ascorbate. Supernatant obtained after precipitation of proteins by $10 \%$ trichloroacetic acid and sedimentation $(2000 \mathrm{~g} \times 10 \mathrm{~min})$ was used for HPLC measurements. A Hypersil column $(5-\mu \mathrm{m}$ particle size, $4.6 \times 200 \mathrm{~mm}$; Hewlett Packard, Palo Alto, CA, U.S.A.) and a mobile phase of 1:24 methanol-water adjusted to $\mathrm{pH} 3.0$ by acetic acid at a flow rate of $1.0 \mathrm{~mL} / \mathrm{min}$ were used. A Shimadzu LC-10A HPLC system was used with an LC-600 pump and an SPD-10A UV detector (all from Shimadzu, Kyoto, Japan; detection was by absorbance at $264 \mathrm{~nm}$ ). Under these conditions, the retention time for ascorbate was $3.1 \mathrm{~min}$. The ascorbate peak was completely eliminated by the addition of ascorbate oxidase to CSF.

EPR measurements of ascorbate radical formation. EPR measurements of ascorbate radicals were performed using a JEOL-RE1X spectrometer (JEOL, Tokyo, Japan) at $25^{\circ} \mathrm{C}$ in gas-permeable Teflon tubing ( $0.8 \mathrm{~mm}$ internal diameter, 0.013 $\mathrm{mm}$ thickness; Zeus Scientific, Raritan, NJ, U.S.A.). The tube ( $\sim 8 \mathrm{~cm}$ in length) was filled with $60 \mu \mathrm{L}$ of CSF, folded, and placed in an open $3 \mathrm{~mm}$ internal diameter EPR quartz tube in such a way that all of the sample was within the effective microwave irradiation area. The spectra were recorded at 3351 $\mathrm{G}$ center field, $10 \mathrm{~mW}$ power, $0.79 \mathrm{G}$ field modulation, $50 \mathrm{G}$ sweep width, 4000 receiver gain, and $0.1 \mathrm{~s}$ time constant. Spectra were collected using EPRware software (Scientific Software Services, Bloomington, IL, U.S.A.).

Statistical analysis. Data are shown as mean \pm SEM. Differences in antioxidant reserves and markers of oxidative stress were determined using ANOVA and the StudentNewman-Keuls test for posthoc comparison between TBI and control in each case. Statistical significance was set at $p<$ 0.05 .

Table 1. Patients with TBI

\begin{tabular}{|c|c|c|c|c|c|}
\hline Patient & Age & Sex & Mechanism of injury & $\begin{array}{c}\text { Initial } \\
\text { GCS score }\end{array}$ & Outcome \\
\hline $\mathrm{T} 1$ & $16 \mathrm{y}$ & $\mathrm{F}$ & Fall & 7 & Survived \\
\hline $\mathrm{T} 2$ & $14 \mathrm{y}$ & M & Auto-pedestrian accident & 8 & Survived \\
\hline $\mathrm{T} 3$ & $11 \mathrm{y}$ & M & Fall & 4 & Survived \\
\hline $\mathrm{T} 4$ & $10 \mathrm{y}$ & $\mathrm{F}$ & Auto-bicycle accident & 5 & Survived \\
\hline T5 & $10 \mathrm{y}$ & $\mathrm{F}$ & Auto-pedestrian accident & 5 & Survived \\
\hline $\mathrm{T} 6$ & $8 \mathrm{y}$ & $\mathrm{F}$ & Fall & 5 & Survived \\
\hline T9 & $18 \mathrm{mo}$ & $\mathrm{F}$ & Fall & 7 & Survived \\
\hline $\mathrm{T} 10$ & $2 \mathrm{mo}$ & M & Child abuse & 4 & Died \\
\hline T11 & $2 \mathrm{mo}$ & $\mathrm{F}$ & Child abuse & 7 & Survived \\
\hline
\end{tabular}




\section{RESULTS \\ Patient Demographics}

Demographic and clinical parameters of TBI patients are shown in Table 1. Age ranged from 2 mo to $16 \mathrm{y}$. There were five male and six female patients. Mechanism of injury included both accidental injury and child abuse. Initial GCS score ranged from 3 to 8 . Nine patients out of 11 survived.

\section{Biochemical Markers of Oxidative Stress in CSF after TBI}

$\boldsymbol{F}_{2}$-isoprostane. $\mathrm{F}_{2}$-isoprostanes are bioactive cyclopentanone prostaglandin-like compounds produced in vivo by free radical peroxidation of arachidonyl-containing lipids, and represent the most reliable lipid biomarker of oxidative stress (34). $\mathrm{F}_{2}$-isoprostane levels in CSF were 9-fold higher in subjects on d 1 after TBI $(93.8 \pm 30.82 \mathrm{pg} / \mathrm{mL})$ compared with controls $(7.62 \pm 1.79 \mathrm{pg} / \mathrm{mL}, p<0.05)$ (Fig. 1). The content of $\mathrm{F}_{2}$-isoprostane in CSF obtained from control subjects was similar to that previously reported (35). The concentrations of $\mathrm{F}_{2}$-isoprostane were 2.5- and 4-fold higher than control on $\mathrm{d} 2$ and d 5-7 after TBI, respectively.

Protein sulfhydryl oxidation. Free radical attack on proteins results in oxidation of their sulfhydryl groups. CSF concentration of protein sulfhydryls was about 3-fold lower on d 5-7 $(5.57 \pm 1.08 \mathrm{nmol} / \mathrm{mg}$ protein) after TBI than controls (13.5 \pm $3.2 \mathrm{nmol} / \mathrm{mg}$ protein), however, this difference was not statistically significant (Fig. 2).

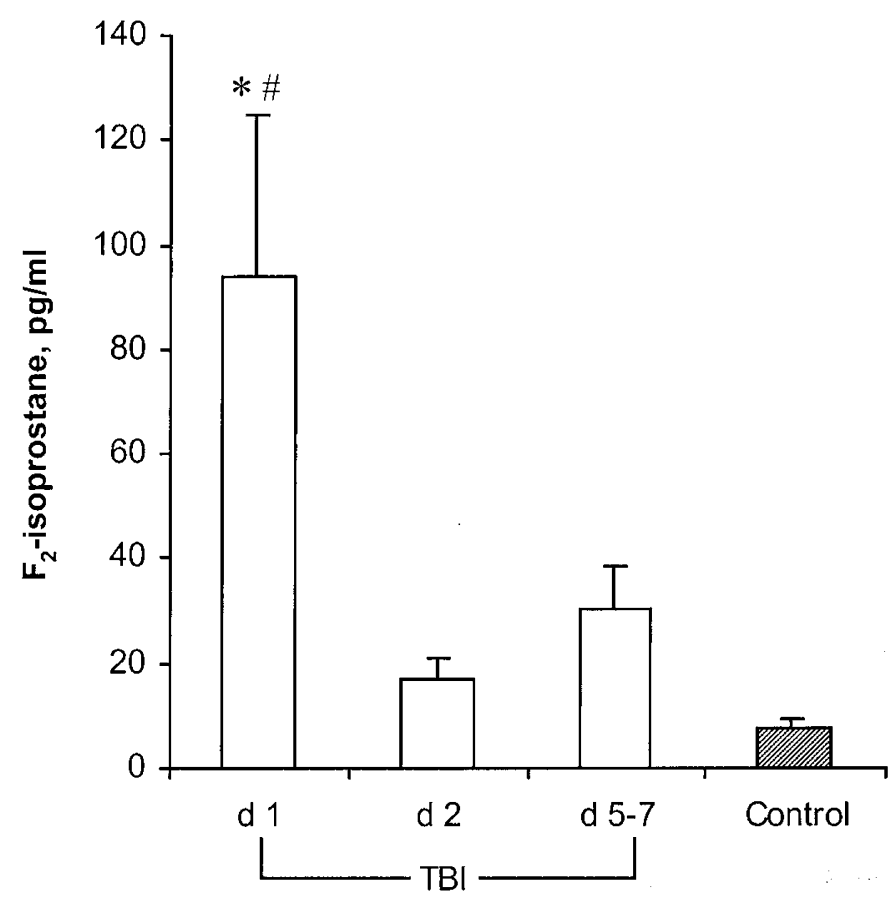

Figure 1. Effect of TBI on $\mathrm{F}_{2}$-isoprostane-containing lipids in CSF. $\mathrm{F}_{2}$ isoprostane levels in infants and children were markedly increased on $\mathrm{d} 1 \mathrm{after}$ TBI $\left({ }^{*} p<0.05 v s\right.$ control, $\# p<0.05$ vs TBI d 2 and $\left.\mathrm{d} 5-7\right)$.

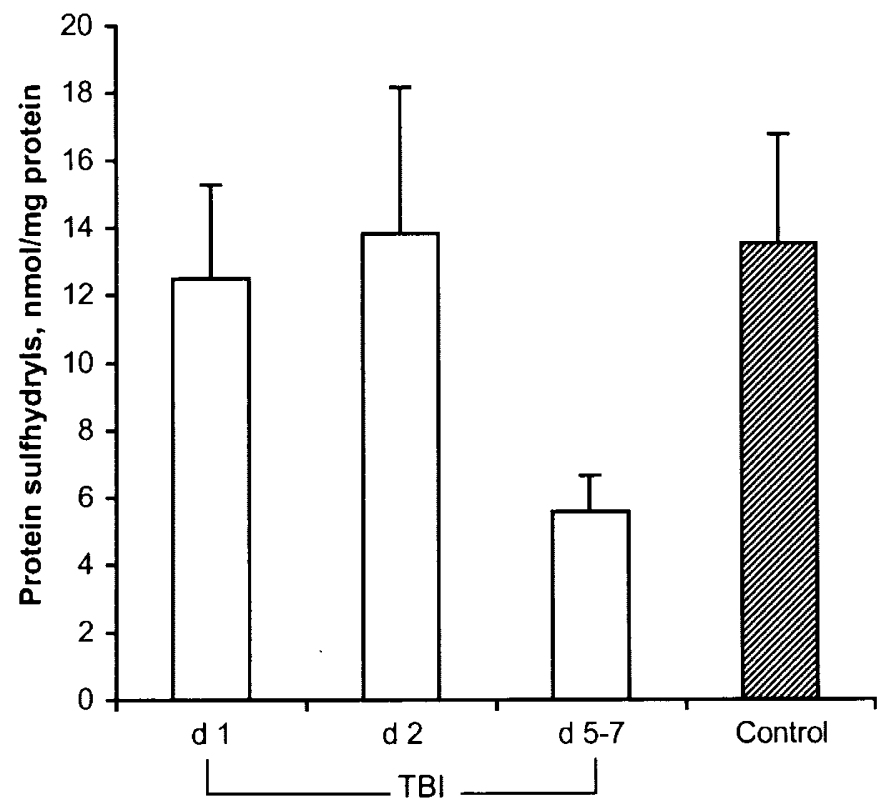

Figure 2. Effect of TBI on content of protein sulfhydryls in CSF. Concentrations of protein sulfhydryls were lower on d 5-7 after TBI compared with controls, but this difference was not significant $(p=0.287)$.

\section{Antioxidant Status of CSF after TBI}

Total antioxidant reserve. The lag period produced by CSF from control subjects was significantly greater than that observed in the presence of CSF from TBI patients at all times after injury, indicating depletion of antioxidant reserve after TBI (Fig. 3a). The luminol-enhanced chemiluminescence assay revealed a $25-50 \%$ reduction in total antioxidant reserve versus control. Sustained depletion of total antioxidant reserve was suspected because the greatest decrease was observed on d 5-7, compared with controls (Fig. 3b).

Ascorbate. Ascorbate concentrations, analyzed by HPLC, in CSF were 3-, 8-, and 10-fold lower in subjects on d 1 (52.98 \pm 8.0
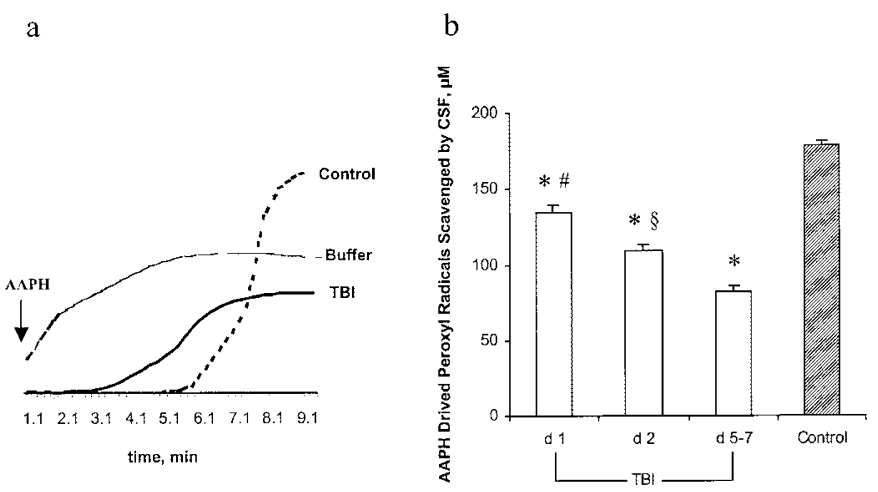

Figure 3. Effect of TBI on total antioxidant reserve. CSF was subjected to free radical attack from peroxyl radicals generated by AAPH in the presence of a reporter molecule, luminol. (a) Typical chemiluminescence responses obtained from CSF of control and TBI patients. The chemiluminescence is delayed in the presence of CSF by quenching of peroxyl radicals by endogenous antioxidants. The duration of the lag period produced by CSF from control subjects was significantly greater than that observed in TBI patients, indicating depletion of antioxidant reserve after TBI. (b) Total antioxidant reserve decreased by $25-50 \%$ at all points tested after TBI $\left({ }^{*} p<0.05 v \mathrm{~s}\right.$ control, $\# p<0.05$ vs TBI d 2 and d 5-7, $\$ p<0.05$ vs TBI d 5-7). 


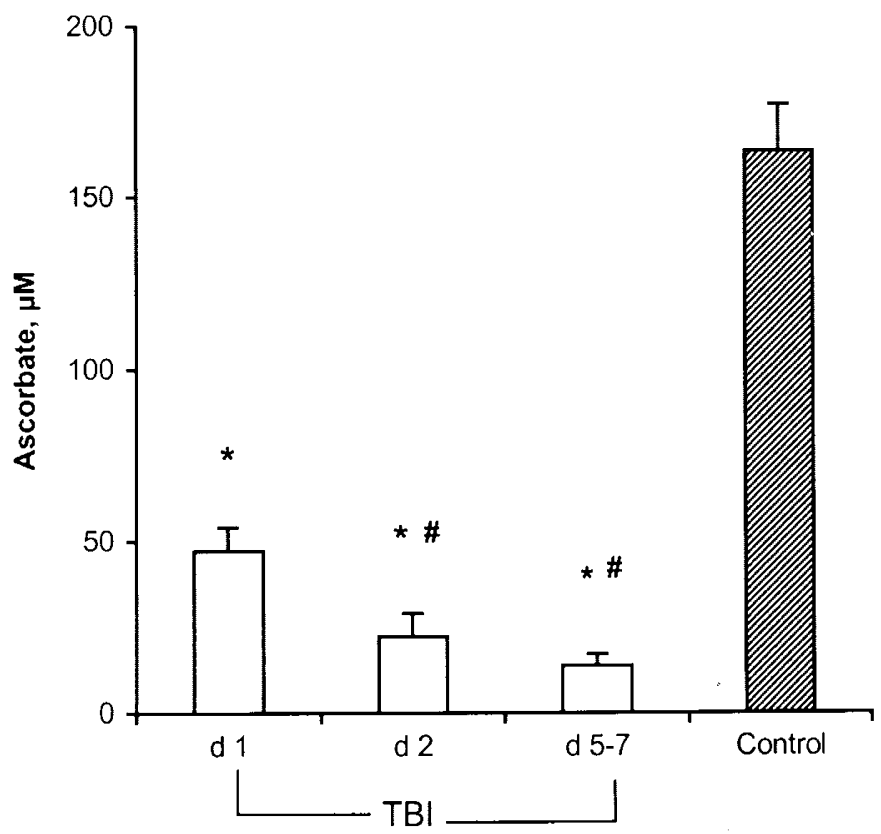

Figure 4. Effect of TBI on ascorbate concentration in CSF. Ascorbate concentrations were 3-, 8-, and 10-fold lower in subjects with TBI on d 1, d 2, and $\mathrm{d} 5-7$, respectively, compared with controls $\left({ }^{*} p<0.05\right.$ vs control, $\# p<$ 0.05 vs TBI d 1).

$\mu \mathrm{M}), \mathrm{d} 2(18.9 \pm 6.9 \mu \mathrm{M})$, and $\mathrm{d} 5-7(13.7 \pm 5.1 \mu \mathrm{M})$ after TBI compared with controls $(163.8 \pm 21.0 \mu \mathrm{M}, p<0.05)$, respectively (Fig. 4). The concentration of ascorbate in CSF obtained from control subjects was similar to that previously reported (36).

GSH. GSH levels increased on $\mathrm{d} 1(5.79 \pm 2.21 \mu \mathrm{M})$ then progressively decreased on $\mathrm{d} 2(3.49 \pm 1.58 \mu \mathrm{M})$ and $\mathrm{d} 5-7$ $(0.19 \pm 0.05 \mu \mathrm{M})$ after TBI compared with controls $(1.2 \pm$ $0.16 \mu \mathrm{M}$ ) (Fig. 5). The content of GSH in CSF obtained from control subjects was similar to that previously reported (37).

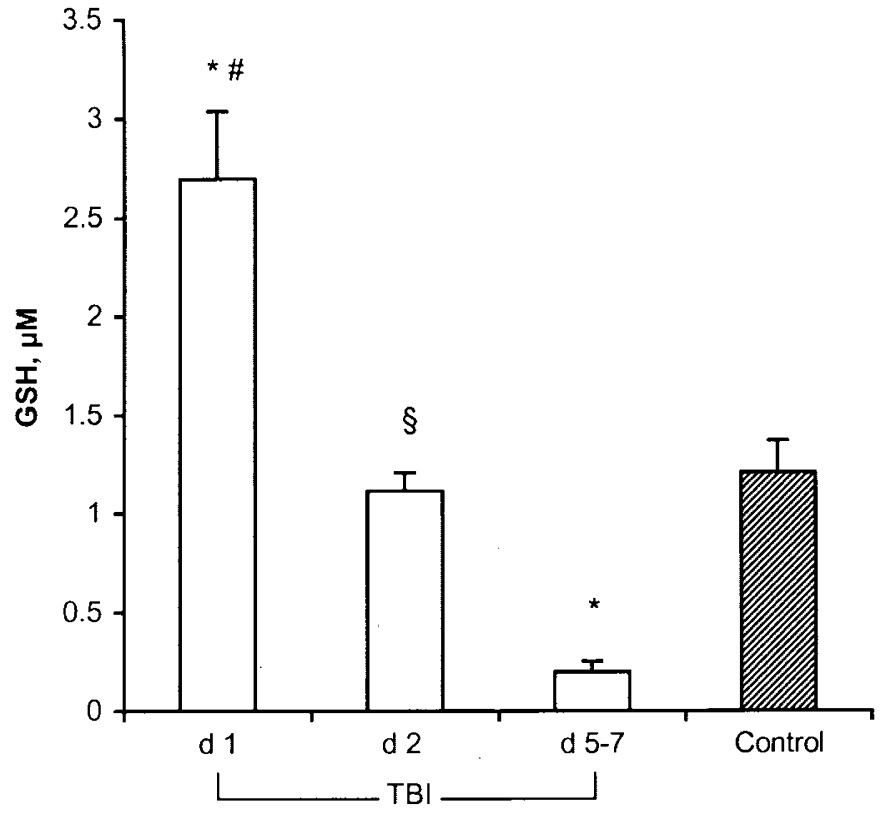

Figure 5. Effect of TBI on content of GSH in CSF. GSH levels increased on $\mathrm{d} 1$, then progressively decreased $\left({ }^{*} p<0.05\right.$ vs control, $\# p<0.05$ vs TBI d 2 and $\mathrm{d} 5-7, \S p<0.05$ vs TBI d 5-7).

\section{Detection of Ascorbate Radicals in CSF after TBI}

In light of our results showing both accumulation of biomarkers of oxidative stress and depletion of antioxidant reserves in CSF after TBI, we also attempted to directly detect formation of free radicals in CSF after TBI. Generation of ascorbate radical is regarded as a marker of free radical-mediated oxidative stress (38). We anticipated that ascorbate radical could be detected in CSF because ascorbate oxidation was occurring as a result of TBI. Typical spectra for ascorbate radicals detected by ESR are shown in Figure 6. Relatively large ascorbate radical signals were detectable in CSF from TBI patients. In control patients, ascorbate radical signals had a wide range in magnitude but generally tended to be smaller than TBI patients. Two types of responses were detected in EPR spectra of CSF from TBI patients. First, a large ascorbate radical signal was detected, which decreased slowly over time by factor(s) oxidizing ascorbate. When deferoxamine (an iron chelator) and bathocuproine sulfonate (a copper chelator) were sequentially added to CSF, in an effort to delineate possible free transition metal ions causing ascorbate oxidation, the magnitude of the signal did not change (data not shown),

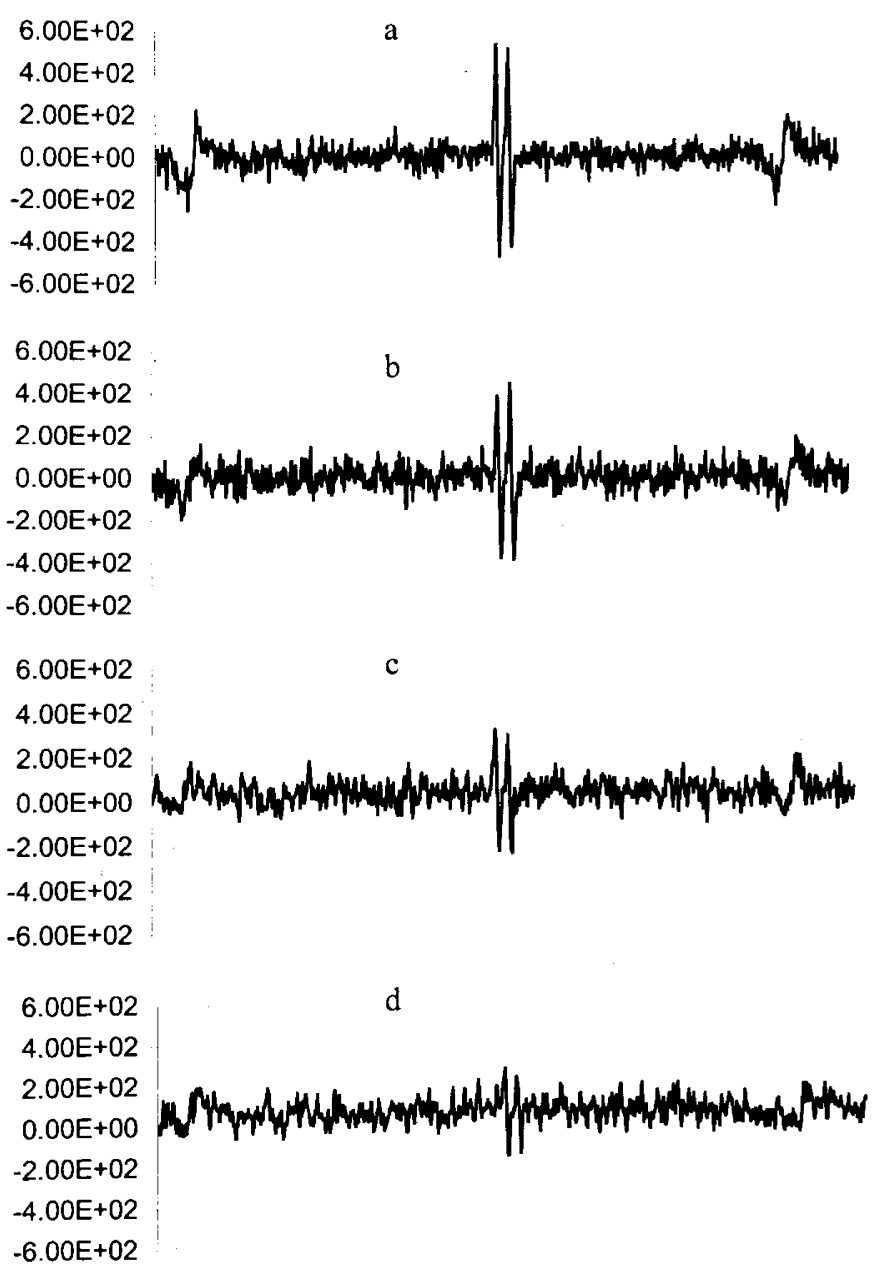

Figure 6. Typical EPR spectra of CSF obtained from $(a)$ d 1 after TBI, $(b) \mathrm{d}$ 2 after TBI, (c) d 5-7 after TBI, and (d) control. Larger ascorbate radical signals were detectable in the initial EPR spectra of CSF from TBI patients compared with controls. 
implying that factors other than free transition metal ions were responsible for ascorbate oxidation. In other TBI cases, ascorbate radical signal was not detected by EPR in CSF, presumably because the ascorbate concentration in the sample was very low. Supporting this possibility, a good correlation between ascorbate concentration and magnitude of ascorbate radical signal was observed in TBI samples (Fig. 7). These data are consistent with marked oxidative stress after TBI and an important antioxidant response to this oxidative stress by ascorbate.

\section{DISCUSSION}

Biomarkers of oxidative stress in CSF after TBI. Enhanced oxidative stress associated with increased production of free radicals has been implicated in experimental TBI-induced disruption of neuronal homeostasis $(7,9,10,39)$. Detailed quantitative assessments of biomarkers of oxidative stress as well as depletion of antioxidant reserves after TBI in humans, however, have not been conducted. The nature of free radical intermediates generated and the sources of free radicals have also not been identified. Therefore, we designed a comprehensive study of clinical TBI-induced oxidative stress, including evaluation of several biochemical markers of oxidative stress coupled with assays of antioxidant reserve, individual antioxidants, and free radical intermediates in CSF. Overall, our findings clearly demonstrate that TBI is accompanied by accumulation of biomarkers of oxidative stress in lipids and severe depletion of antioxidant reserves, including ascorbate.

We found that in CSF the content of $\mathrm{F}_{2}$-isoprostane was markedly increased after TBI compared with control on d 1, and remained higher than control throughout the study period.

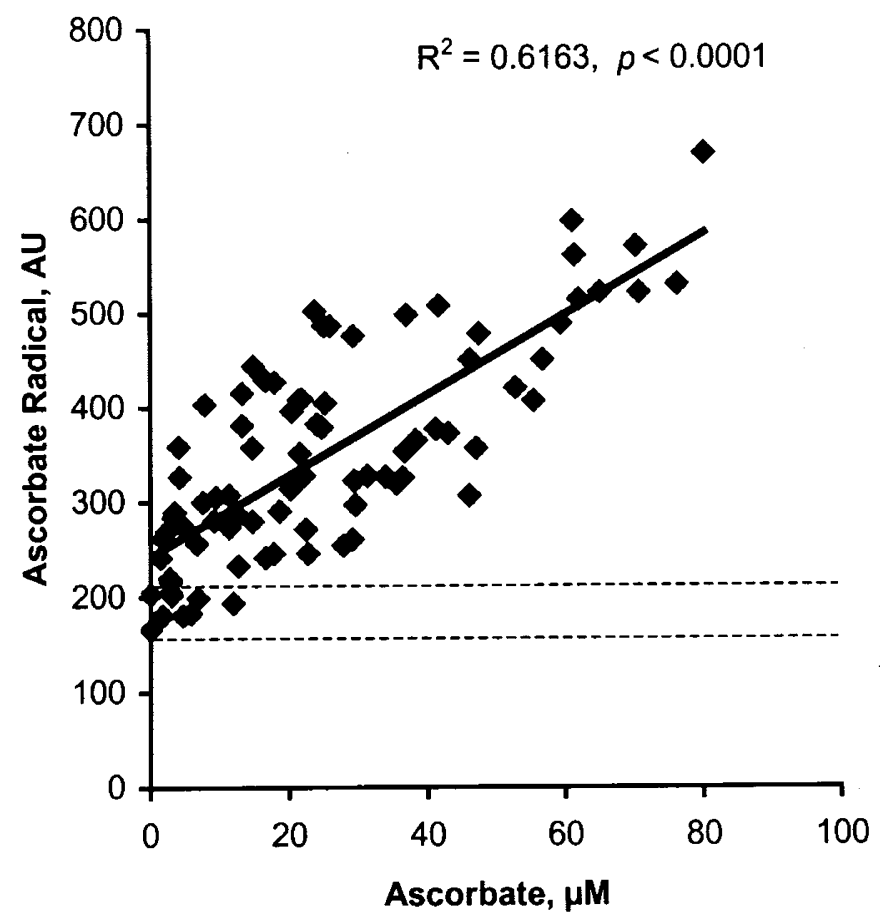

Figure 7. Correlation between ascorbate concentration and magnitude of ascorbate radical EPR signal in CSF after TBI. The area between the two dashed horizontal lines represents the background EPR signal.
Advantages to quantifying $\mathrm{F}_{2}$-isoprostanes as an index of oxidative stress are their specificity for lipid peroxidation, their chemical stability, and the small CSF volumes $(50 \mu \mathrm{L})$ required for their detection. Interestingly, the only patient who had levels of $\mathrm{F}_{2}$-isoprostane comparable to controls was treated with therapeutic hypothermia. Therapeutic hypothermia is known to decrease oxidative damage (40).

The amount of protein sulfhydryl groups in CSF on $\mathrm{d} 1$ and 2 after TBI was comparable to that in controls. This could be explained by possible regeneration of protein sulfhydryl groups. However, protein sulfhydryl concentration tended to decrease on d 5-7 after TBI compared with controls, indicating a decrease in protein sulfhydryl regeneration, likely related to the progressive decrease in antioxidant reserves after TBI.

Antioxidant reserves in CSF after TBI. Total antioxidant reserves in CSF were depleted throughout the study period. A similar time course was also observed for ascorbate. In a previous study by Brau et al. (41), a 2.5- to 3-fold decrease in ascorbate concentration was shown in five adult TBI patients. There is a high concentration of ascorbate in both the gray and white matter of the brain, and the choroid plexus has a specific active transport system that increases ascorbate concentrations in CSF to a level several times higher than plasma (42). Ascorbate is highly effective in trapping free radicals and preventing the formation of lipid hydroperoxides (43) that can be generated during TBI. Ascorbate also acts as a neuromodulator, facilitating the release of neurotransmitters and inhibiting neurotransmitter binding to receptors (44).

However, in vitro, ascorbate can also exert pro-oxidant properties. In the presence of free iron or copper ion, this pro-oxidant activity derives from the ability of ascorbate to reduce iron(III) and copper(II) to iron(II) and copper(I), respectively, and to generate reactive oxygen-derived species (45). A major factor favoring pro-oxidant effects of ascorbate would presumably be the availability of catalytic free transition metal ions. Brain injury can lead to release of catalytic transition metal ions (15). Thus, after TBI it is possible that ascorbate could exert pro-oxidant effects. Indeed, it can be argued that the decline in ascorbate during oxidative stress is beneficial not only because ascorbate is helping to scavenge radicals and recycle $\alpha$-tocopherol, but also because ascorbate removal minimizes its potential pro-oxidant interactions with metal ions released by tissue damage. Opposing this possibility, a prooxidant interaction of ascorbate with free transition metal ions in CSF, as assessed by addition of deferoxamine and bathocuproine sulfonate, was not detected in our experiments.

The marked decrease in CSF ascorbate concentrations after TBI in our study may have other possible explanations. First, TBI might disrupt the blood-brain barrier and decrease the concentration gradient for ascorbate accumulation. As previously stated, brain tissue ascorbate concentration is greater than in plasma, and movement of ascorbate from brain to blood could occur. Second, because patients are not fed until 48-72 $\mathrm{h}$ after TBI in our institution and standard intensive care unit protocol in our center includes addition of ascorbate to parenteral nutrition every other day, low plasma levels of ascorbate could contribute to sustained decreases in CSF levels. This alternative seems to be an unlikely contributing factor. The 
TBI patients were studied over the first $7 \mathrm{~d}$ after injury. The biologic half-life of ascorbate, which is inversely related to the daily intake, is $14-40 \mathrm{~d}$ in humans with normal intake. However, the half-life of ascorbate in the brain during conditions of increased oxidative stress is unknown. In future studies, we plan to measure plasma and CSF levels of ascorbate concurrently in TBI patients treated with current standard of care versus addition of supplemental ascorbate. Third, trauma could induce cerebral energy failure, reducing the transport of ascorbate at the choroid plexus. To our knowledge, there are no experimental data to support this alternative. Fourth, ascorbate may have been consumed by the free radicals associated with TBI. This would be the most likely scenario and one that provides a unifying explanation for all of the results of this study.

GSH content in CSF increased initially and then decreased below control levels on d 5-7 after TBI. This may be explained by the initial release of GSH into CSF from injured cells followed by progressive oxidative loss. One would also expect GSH to be depleted eventually in the restoration of brain ascorbate levels. This recycling mechanism is critical in maintaining ascorbate levels by reducing ascorbate radical at the expense of GSH consumption (46). This reaction is dependent on the concentration of these antioxidants and/or the enzymes that maintain them in their reduced form (47).

Free radical intermediates in TBI. The results in laboratory models of brain injury $(9,39)$ and our findings in clinical TBI demonstrate that enhanced formation of ascorbate radicals is a characteristic feature of TBI. Our previous work in experimental TBI also showed that depletion of ascorbate is a prerequisite for detection of other radicals by spin trapping. Ascorbate is the primary antioxidant essential for protection of the brain against TBI-induced oxidative stress (9). Hence, monitoring of ascorbate depletion and ascorbate radical production in the brain during oxidative insult may be a valuable method for assessment of antioxidant status and degree of oxidative injury.

Clinical implications. To date, there have been no comprehensive studies assessing the occurrence of free radical intermediates and endogenous defense mechanisms that protect against oxidative stress in CSF after TBI in either adults or infants and children. Antioxidants are ultimately reductants (electron donors) that may and will be consumed unless the major cause of oxidative stress is established and eliminated. Two large clinical trials in TBI using antioxidants (PEG-SOD and tirilazad) showed largely negative results $(25,30)$. However, these two agents appear to have very limited brainpenetrating ability (48). Unfortunately, no confirmation of a reduction in oxidative stress or free radical damage with treatment was shown in these studies. Indeed, free radicalrelated biochemical markers were not addressed. Our findings suggest that quantification of biomarkers of oxidative stress and antioxidant status of CSF may reflect severity of TBI and provide a rational basis for selection, evaluation, and monitoring of antioxidant strategies such as brain-penetrating antioxidants (i.e. nitroxides) or other therapies such as hypothermia, anti-excitotoxic, anti-apoptotic and anti-inflammatory agents for clinical trials in TBI.
Limitations of the study. Despite the small sample size and considerable variability in patient age, mechanism of injury, and treatment, statistical significance was achieved between patients with TBI and controls for all the measurements except protein sulfhydryls. This highlights the robust nature of the alterations in markers of oxidative damage after TBI. In our study sample ( $n=11$ patients), two children died and two infants suffered from child abuse, limiting the analysis of the relationship of oxidative stress to outcome and/or mechanism of injury. Further studies with a larger sample size, including a comprehensive analysis of biochemical data as it relates to outcome, mortality, mechanism of injury (accidental trauma versus child abuse), and age, are needed. In future studies, the association between oxidative stress and physiologic parameters such as intracranial pressure, cerebral perfusion pressure, and cerebral blood flow should also be assessed using serial samples of CSF and online acquisition of physiologic data at the bedside. With a larger population size, these findings may be directly related to either severity of injury or outcome. In addition, the impact of CSF drainage on these markers remains to be investigated because large volumes of CSF drainage are frequently seen as part of the treatment of these infants and children with severe TBI. Assessment of the relationship between markers of oxidative stress and associated mechanisms of secondary damage such as apoptosis (49), excitotoxicity (50), and inflammation (1) could also be revealing.

We used CSF samples taken from different sitesventricular or lumbar. We understand that the control CSF samples were not ideal. These were the best samples that could be obtained, however, because it would have been unethical to perform simultaneous lumbar and ventricular sampling in patients in this study. In addition, in children without TBI, ventriculostomies are placed for treatment of hydrocephalus, for ventriculoperitoneal shunt revision in the settings of infection or shunt failure, and after surgical resection of brain tumors. Because abnormal values for oxidative stress and other markers have been reported in each of these conditions (51, 52), they represent poor controls. Shunt failure often has a component of compression ischemia, and tumors and infections are associated with increases in CSF levels of biochemical markers of oxidative stress $(51,52)$. Finally, many of the biomarkers assessed in our study demonstrated a clear time course within the injury group, with temporary increases or decreases. Taken together, all of these factors argue strongly against artifactual derangements in markers of oxidative stress and/or antioxidants as a result of the use of ventricular samples.

\section{CONCLUSIONS}

Severe TBI in infants and children is accompanied by marked and progressive compromise of antioxidant defenses and free radical-mediated lipid peroxidation, suggesting that these markers could be used to assess the effect of therapies on oxidative stress in patients after TBI. Defining the role of oxidative stress in the pathophysiology of TBI in infants and children could help with the development of novel, clinically applicable therapies. 


\section{REFERENCES}

1. Kochanek PM, Clark RSB, Ruppel RA, Adelson PD, Bell MJ, Whalen MJ, Robertson CL, Satchell MA, Seidberg NA, Marion DW, Jenkins LW 2000 Biochemical, cellular and molecular mechanisms in the evolution of secondary damage after severe TBI in infants and children: lessons learned from the bedside. Pediatr Crit Care Med 1:4-19

2. Ikeda Y, Long DM 1990 The molecular basis of brain injury and brain edema: the role of oxygen free radicals. Neurosurgery 27:1-14

3. Kontos HA, Wei EP 1986 Superoxide production in experimental brain injury. J Neurosurg 64:803-807

4. Kontos HA, Wei EP 1993 Hydroxyl radical-dependent inactivation of guanylate cyclase in cerebral arterioles by methylene blue and by LY85583. Stroke 24:427-434

5. Wei EP, Kontos HA, Beckman JS 1996 Mechanisms of cerebral vasodilation by superoxide, hydrogen peroxide, and peroxynitrite. Am J Physiol 271(3 Pt 2):H1262H1266

6. Feuerstein GZ, Wang X, Barone FC 1997 Inflammatory gene expression in cerebral ischemia and trauma. Potential new therapeutic targets. Ann N Y Acad Sci 825:179-193

7. Hall ED, Yonkers PA, McCall JM, Braughler JM 1988 Effects of the 21-aminosteroid U74006F on experimental head injury in mice. J Neurosurg 68:456-461

8. Kontos CD, Wei EP, Williams JI, Kontos HA, Povlishock JT 1992 Cytochemical detection of superoxide in cerebral inflammation and ischemia in vivo. Am J Physiol 263(4 Pt 2):H1234-H1242

9. Tyurin VA, Tyurina YY, Borisenko GG, Sokolova TV, Ritov VB, Quinn PJ, Rose M, Kochanek P, Graham SH, Kagan VE 2000 Oxidative stress following TBI in rats: quantitation of biomarkers and detection of free radical intermediates. J Neurochem $75: 2178-2179$

10. Wada K, Alonso OF, Busto R, Panetta J, Clemens JA, Ginsberg MD, Dietrich WD 1999 Early treatment with a novel inhibitor of lipid peroxidation (ly341122) improves histopathological outcome after moderate fluid percussion brain injury in rats. Neurosurgery 45:601-608

11. Shohami E, Beit-Yannai E, Horowitz M, Kohen R 1997 Oxidative stress in closed head injury: brain antioxidant capacity as an indicator of functional outcome. J Cereb Blood Flow Metab 17:1007-1019

12. Ames BN, Shigenega MT, Hagen M 1993 Oxidants, antioxidants and the degenerative diseases of aging. Proc Natl Acad Sci U S A 90:7915-7922

13. Evans PH 1993 Free radicals in brain metabolism and pathology. Br Med Bull 49:557-587

14. Watson BD 1993 Evaluation of concomitance of lipid peroxidation in experimental models of cerebral ischemia and stroke. Prog Brain Res 96:69-95

15. Halliwell B 1992 Reactive oxygen species and the central nervous system. J Neurochem 59:1609-1622

16. Amstad PA, Krupitza G, Cerutti PA 1992 Mechanisms of c-fos induction by active oxygen. Cancer Res 52:3952-3960

17. Lander HM, Ogiste JS, Teng KK, Novogrodsky A 1995 p2 $1^{\text {ras }}$ as a common signaling target of reactive oxygen radicals and cellular redox stress. J Biol Chem 270:2119521198

18. Hensley K, Kent AR, Gabbita SP, Salsman S, Floyd RA 2000 Reactive oxygen species, cell signaling, and cell injury. Free Radic Biol Med 28:1456-1462

19. Yao Y, Yin D, Jas GS, Kuczer K, Williams TD, Schoneich C, Squier TC 1996 Oxidative modification of a carboxyl-terminal vicinal methionine in calmodulin by hydrogen peroxide inhibits calmodulin-dependent activation of the plasma membrane calcium-ATPase. Biochemistry 35:2767-2787

20. Chan PH 1996 Role of oxidants in ischemic brain damage. Stroke 27:1124-1129

21. Chan PH, Longer S, Fishman RA 1987 Protective effects of liposome-entrapped superoxide dismutase on posttraumatic brain edema. Ann Neurol 21:540-547

22. Inci S, Ozcan O, Kilinic K 1998 Time-level relationship for lipid peroxidation and the protective effect of $\alpha$-tocopherol in experimental mild and severe brain injury. Neurosurgery 43:330-335

23. Muizelaar JP, Marmarou A, Young HF, Choi SC, Wolf A, Schneider RL, Kontos HA 1993 improving the outcome of severe head injury with oxygen radical scavenger polyethylene glycol-conjugated superoxide dismutase: a phase II trial. J Neurosurg 78:375-382

24. Sen S, Goldman H, Morehead M, Murphy S, Phillis JW 1993 Oxypurinol inhibits free radical release from the cerebral cortex of closed head injured rats. Neurosci Lett 162:117-120

25. Wahlgren NG 1997 A review of earlier clinical studies on neuroprotective agents and current approaches. In: Green AR, Cross AJ (eds) Neuroprotective Agents and Cerebral Ischemia. Academic Press, San Diego, pp 337-363

26. Imaizumi S, Wollworth V, Fishman RA, Chan PH 1990 Liposome entrapped superoxide dismutase reduces cerebral infarction in cerebral ischemia in rats. Stroke 21:1312-1317
27. Young W, Wojak JC, Decrescito V 1988 21-Aminosteroid reduces ion shifts and edema in the rat middle cerebral artery occlusion model of regional ischemia. Stroke 19:1013-1019

28. Zuccarello M, Marsch JT, Schmitt G, Woodward J, Anderson DK 1980 Effect of the 21-aminosteroid U-74006F on cerebral vasospasm following subarachnoid hemorrhage. J Neurosurg 71:98-104

29. Hall E 1987 Beneficial effects of the 21-aminosteroid U74006F in acute central nervous system trauma and in hypovolemic shock. Acta Anaesthesiol Belg 38:421425

30. Marshall LF, Maas AIR, Marshall SB, Bricolo A, Fearnside M, Iannotti F, Klauber MR, Lagarrigue J, Lobato R, Persson L, Pickard JD, Piek J, Servadei F, Wellis GN, Morris GF, Means ED, Musch B 1998 A multicenter trial on the efficacy of using tirilazad mesylate in cases of head injury. J Neurosurg 89:519-525

31. Marshall LF, Marshall SB 1995 Pitfalls and advances from the international tirilazad trial in moderate and severe head injury. J Neurotrauma 12:929-932

32. Langmuir ME, Yang JR, Durand RE 1996 New thiol active fluorophores for intracellular thiols and glutathione measurement. In: Slavik J (ed) Fluorescence Microscopy and Fluorescent Probes. Plenum Press, New York, pp 229-234

33. Tyurina YY, Tyurin VA, Yalowich J, Quinn PJ, Claycamp HG, Schor NF, Pitt BR, Kagan VE 1995 Phenoxyl radicals of etoposide (VP-16) can directly oxidize intracellular thiols: protective versus damaging effects of phenolic antioxidants? Toxicol Appl Pharmacol 131:277-288

34. Morrow JD, Awad JA, Boss HJ, Blair IA, Roberts II LJ 1992 Non-cyclooxygenasederived prostanoids ( $\mathrm{F}_{2}$-prostanes) are formed in situ on phospholipids. Proc Natl Acad Sci U S A 89:10721-10725

35. Greco A, Mighnetti L, Sette G, Fieschi C, Levi G 1999 Cerebrospinal fluid isoprostane shows oxidative stress in patients with multiple sclerosis. Neurology 53:18761879

36. Lönnrot K, Metsä-Ketelä M, Molnár G, Ahonen JP, Latvala M, Peltola J, Pietila T, Alho H 1996 The effect of ascorbate and ubiquinone supplementation on plasma and CSF total antioxidant capacity. Free Radic Biol Med 21:211-217

37. Van Hove JL, Lazeyras F, Zeisel SH, Bottiglieri T, Hyland K, Charles HC, Gray L, Jaeken J, Kahler SG 1998 One-methyl group metabolism in non-ketotic hyperglycemia: mildly elevated cerebrospinal fluid homocysteine levels. J Inherit Metab Dis 21:799-811

38. Buettner GR, Jurkiewicz BA 1993 Ascorbate free radical as a marker of oxidative stress: an EPR study. Free Radic Biol Med 14:49-55

39. Awashti D, Church DF, Torbati D, Carey ME, Pryor WA 1997 Oxidative stress following TBI in rats. Trauma 47:575-582

40. Karibe H, Chen FS, Zarow GJ, Gafni J, Graham SH, Chan PH, Weinstein PR 1994 Mild intraischemic hypothermia suppresses consumption of endogenous antioxidants after temporal focal ischemia in rats. Brain Res 649:12-18

41. Brau RH, Garcia-Castiñeiras S, Rifkinson N 1984 Cerebrospinal ascorbic acid levels in neurological disorders. Neurosurgery 14:142-146

42. Spector R, Eells J 1984 Deoxynucleoside and vitamin transport into the central nervous system. Fed Proc 43:196-200

43. Frei B, England L, Ames BN 1989 Ascorbate is an outstanding antioxidant in human blood plasma. Proc Natl Acad Sci U S A 86:6377-6381

44. Rabec GV, Pierce RC 1994 A vitamin as neuromodulator: ascorbate release into the extracellular fluid of the brain regulates dopaminergic and glutamatergic transmission. Prog Neurobiol 43:537-565

45. Halliwell B, Gutteridge JMC 1990 Role of free radicals and catalytic metal ions in human disease: an overview. Methods Enzymol 186:1-85

46. Winkler BS, Orselli SM, Rex TS 1994 The redox couple between glutathione and ascorbic acid: a chemical and physiological perspective. Free Radic Biol Med 17:333-349

47. Meisner A 1992 On the antioxidant effects of ascorbic acid and glutathione. Biochem Pharmacol 44:1905-1915

48. Hall ED, Andrus PK, Smith SL, Fleck TJ, Scherch HM, Lutzke BS, Sawada GA, Althaus JS, Vonvoigtlander PF, Padbury GE, Larson PG, Palmer JR, Bundy GL 1997 Pyrrolopyrimidines: novel brain-penetrating antioxidants with neuroprotective activity in brain injury and ischemia models. J Pharmacol Exp Ther 281:895-904

49. Clark RSB, Kochanek PM, Minzhi C, Watkins SC, Marion DW, Chen J, Hamilton RL, Loeffert JE, Graham SH 1999 Increases in Bcl-2 and cleavage of caspase-1 and caspase-3 in human brain after head injury. FASEB J 13:813-821

50. Ruppel RA, Kochanek PM, Adelson PD, Rose M, Wisniewski SR, Bell MJ, Clark RSB, Marion DW, Graham SH 2001 Excitatory amino acid concentrations in ventricular cerebrospinal fluid after severe traumatic brain injury in infants and children: the role of child abuse. J Pediatr 138:18-25

51. Cobbs CS, Brenman JE, Aldape KD, Bredt DS, Israel MA 1995 Expression of nitric oxide synthase in human central nervous system tumors. Cancer Res 55:727-730

52. Del Bigio MR 1989 Hydrocephalus-induced changes in the composition of cerebrospinal fluid. Neurosurgery 25:416-423 